\title{
Acerca de las dificultades para aceptar que los niños piensan sobre lo escrito
}

\author{
Emilia Ferreiro \\ DIE - CINVESTAV, México
}

(Texto recibido el 12 de enero de 2018, aceptado el 11 de abril de 2018)

DOI: http://doi.org/10.5565/rev/jt13.769

Resumen: Los días 17, 18 y 19 de noviembre del 2016, se realizaron las Jornadas Internacionales de Escritura y Alfabetización, en el marco del décimo aniversario de la Maestría en Escritura y Alfabetización de la Universidad Nacional de La Plata, Argentina. El presente artículo deriva de la conferencia con la que la Dra. Emilia Ferreiro diera cierre a dichas Jornadas. En una exposición amena y rigurosa, la autora analiza dificultades teóricas y metodológicas, de docentes e investigadores, para aceptar que los niños construyen conocimientos sobre lo escrito.

Palabras clave: Investigación evolutiva, adquisición de la lengua escrita, conceptualizaciones infantiles

Abstract: On the $17^{\text {th }}, 18^{\text {th }}$ and $19^{\text {th }}$ of November, 2016, the International Literacy and Writing Conference was held, as part of the commemorations of the $10^{\text {th }}$ anniversary of the Master in Writing and Literacy at the Universidad Nacional de La Plata, Argentina. This article derives from the conference with which Dr. Emilia Ferreiro closed the encounter. The author analyzes theoretical and methodological difficulties faced by teachers and researchers in accepting that children construct knowledge about writing.

Keywords: Developmental research, beginning literacy, children's ideas about written marks

Résumé : Les Journées Internationales de l'Ecriture et de l'Alphabétisation ont eu lieu les 17, 18 et 19 novembre 2016 dans le cadre du dixième anniversaire du Master en Lettres et Alphabétisation de l'Université Nationale de La Plata, Argentine. Le présent article découle du discours de clôture par Mme Emilia Ferreiro. Dans une exposition plaisante et rigoureuse, l'auteur analyse les difficultés théoriques et méthodologiques, des enseignants et des chercheurs, à accepter que les enfants construisent des connaissances sur l'écriture.

Mots-clés : Recherche évolutive, l'écrit avant l'enseignement formel, conceptualisation des enfants à propos de l'écrit 


\section{Introducción}

¿Por qué es tan difícil admitir que los niños piensan? Específicamente, que piensan a propósito de lo escrito. Llevo más de cuarenta años reflexionando y hablando ante públicos muy diversos, en distintos países, y siempre aparece lo mismo: una dificultad muy grande para reconocer la validez y pertinencia de ese pensamiento infantil. Celebran las respuestas de los niños pero no sacan las consecuencias fuertes de los datos que presento y comento. Voy a intentar en esta ocasión un breve recorrido por las dificultades de autoridades, de maestros, de padres y, por supuesto, también de investigadores. Se trata apenas de un punteo de algunas dificultades que me parecen relevantes, sin un ordenamiento jerárquico. Este tema tiene mucho que ver con la construcción de la idea de infancia y los cambios de esa idea a través de los siglos, en Occidente por lo menos (sobre Oriente creo que sabemos muy poco).

En la polifonía del proceso de aprendizaje escolar los niños no son protagonistas, no tienen voz en la historia de este proceso. Las voces son las de quienes conducen el proceso. La voz más próxima es la del docente, quien responde a otras voces más lejanas que no tienen corporeidad: los planes y programas, las metas educativas, los objetivos de aprendizaje, los métodos. Diseños de planes, programas, metas educativas muy pocas veces se formulan teniendo en cuentan el punto de vista de los alumnos, aunque se mencionen los intereses de los niños o jóvenes. Se buscan resultados y el mejor método o procedimiento es el que autoriza resultados evaluables en el menor tiempo posible.

\section{Primera dificultad: produce malestar el descubrir aprendizajes de contenidos escolares que se realizaron fuera del control de un adulto}

Para ilustrar esta dificultad me voy a apoyar en una anécdota de hace ya bastante tiempo, que me quedó grabada y me dejó pensando mucho. Una madre, maestra de primaria, descubre que su hijo aprendió a leer sin que ella se diera cuenta. Me comenta eso y me dice muy angustiada "¿y ahora que hago?" Yo le dije "felicitarlo, aplaudirlo...". Ella me dice "no, pero usted no se da cuenta, aprendió solo”. Yo le digo “¿y cuál es el problema?”. Ella responde "no sabemos cómo aprendió, va a tener problemas”. Yo, muy ingenua en esa época, le digo “ipero por qué?”. Respuesta: "porque aprendió sin método, de cualquier manera". 
Esa anécdota me hizo pensar mucho y me ayuda a plantear ante otros docentes y padres la siguiente pregunta: ¿por qué esta madre y maestra anticipa que su hijo va a tener problemas en lugar de reconocer que su hijo resolvió problemas para aprender a leer? En lugar de pensar que resolvió problemas, anticipa que va a tener problemas porque lo hizo sin la guía de un adulto. “Aprendió sin método, de cualquier manera", eso es lo que me dijo. O sea, de manea salvaje. Los aprendizajes de carácter escolar deben realizarse bajo la supervisión de un adulto competente, caso contrario se anticipan desviaciones o, incluso, patologías. La lectura es uno de esos aprendizajes fundamentales.

\section{Segunda dificultad: aceptar en un diseño de investigación respuestas no previsibles}

¿Qué pasa con los investigadores interesados en la adquisición de la lengua escrita? Lo primero, en los tiempos que son los nuestros, si no se dice en inglés, no existe el investigador ni los datos. Los investigadores que venimos de otras latitudes tenemos una carga bastante pesada: publicar en inglés para tener visibilidad y, simultáneamente, seguir publicando en español, en portugués, en italiano... en las lenguas que no tienen prestigio científico hoy día, para no permitir que el inglés sea la única lengua de comunicación científica. Esa carga tan pesada, obviamente, no la tienen los anglófonos.

Hay poco diseños de investigación experimentalistas, de esos que llaman rigurosos, con procedimientos igualmente rigurosos, que se animen a apartarse de una dicotomía prestablecida, la de respuestas correctas vs respuestas incorrectas. En el gran inventario de las respuestas incorrectas cabe todo, desde las muy pero muy alejadas de la respuesta correcta, hasta las muy próximas a la respuesta correcta. Por eso, varios investigadores, también rigurosos, se han atrevido a clasificar las respuestas incorrectas. Es ya un notable avance. Lo celebro porque eso les complica de inmediato el dar cuenta de los resultados: las cantidades para hacer un buen análisis estadístico disminuyen, etcétera. Pero hay otra razón más profunda, que es de índole epistemológica: la mayoría de los investigadores adhieren a la creencia de que la objetividad se obtiene con la mínima participación del investigador en el proceso de obtención del dato. En el ideal, se delega en un aparato la obtención del dato para que la subjetividad del experimentador no interfiera. Nada de esto es banal. Piaget nos advirtió hace décadas que la objetividad no es un dato de partida, sino un dato de llegada. Para decirlo de modo rápido y comprensible: el sujeto 
objetivo no es el más pasivo, que delega en otros instrumentos la obtención del dato sino el más activo, porque asume el trabajo de coordinación, reconstrucción, integración, en base a las informaciones y teorizaciones previas. Ese es un tema epistemológico de la mayor importancia, que apenas estoy señalando pero no puedo tratar en esta presentación.

\section{Tercera dificultad: admitir que los niños pueden dar razones de comportamientos que, a primera vista, son incongruentes, caóticos o producidos por falta de control}

Preguntar a los niños sobre las posibles razones de algo que a nosotros adultos nos parece totalmente incomprensible es, casi casi, tratarlos como si fueran adultos. Pues sí, de eso se trata justamente, de entablar un diálogo de tú a tú con ellos, tratándolos como partenaires intellectuels, una expresión bien difícil de traducir al español. Algo así como "interlocutores válidos al nivel intelectual" (Ferreiro, 1997). Esa es una de las claves principales de las entrevistas conducidas con método clínico-crítico. El adulto se muestra realmente interesado en los por qué de las respuestas, pero no pregunta por qué con la actitud de alguien que llena un cuestionario, sino que dice algo así como "la verdad, no consigo entenderte, ¿me podrías explicar otra vez?” Eso, con genuina actitud de un interlocutor que necesita y quiere comprender. Los niños son extremadamente sensibles a esos matices de la interlocución. Preguntar a los niños sobre la razón de sus respuestas es, muchas veces, la única pista para distinguir entre comportamientos azarosos y comportamientos intencionales.

Tengo algunos ejemplos que, me parece, son bastante convincentes. Son ejemplos de una muy buena tesis de doctorado reciente realizada en México por Amira Dávalos. Uno de los materiales que utilizamos fue una versión en historieta de la clásica fábula de Esopo El león y el ratón. La anécdota es conocida (Ilustración 1). Un león está dormido y, sin querer, un ratoncito lo despierta. El león se pone furioso y dice: “cómo te atreves a despertarme”. De pronto, parece que el ratoncito va a desaparecer en las fauces del león, pero apela a su ingenio y le dice: "has pensando rey león que quizás alguna vez podré salvarte la vida". Entonces, el león dice “a quién se le ocurre, un ratón salvando la vida de un león”. El ratón aprovecha para escaparse. Un tiempo después el león cae en una red, pide auxilio y aparece el ratoncito, roe la red, libera al león quien dice "gracias ratoncito". Final de la historia. 
Eso presentado todo con mayúsculas, sin puntuación (ver Ilustración 1). Amira interrogó, en parejas, a chicos de $2^{\circ}, 4^{\circ}$ y $6^{\circ}$ grado de primaria, en escuelas públicas, y los estimuló a introducir la puntuación que les pareciera necesaria.

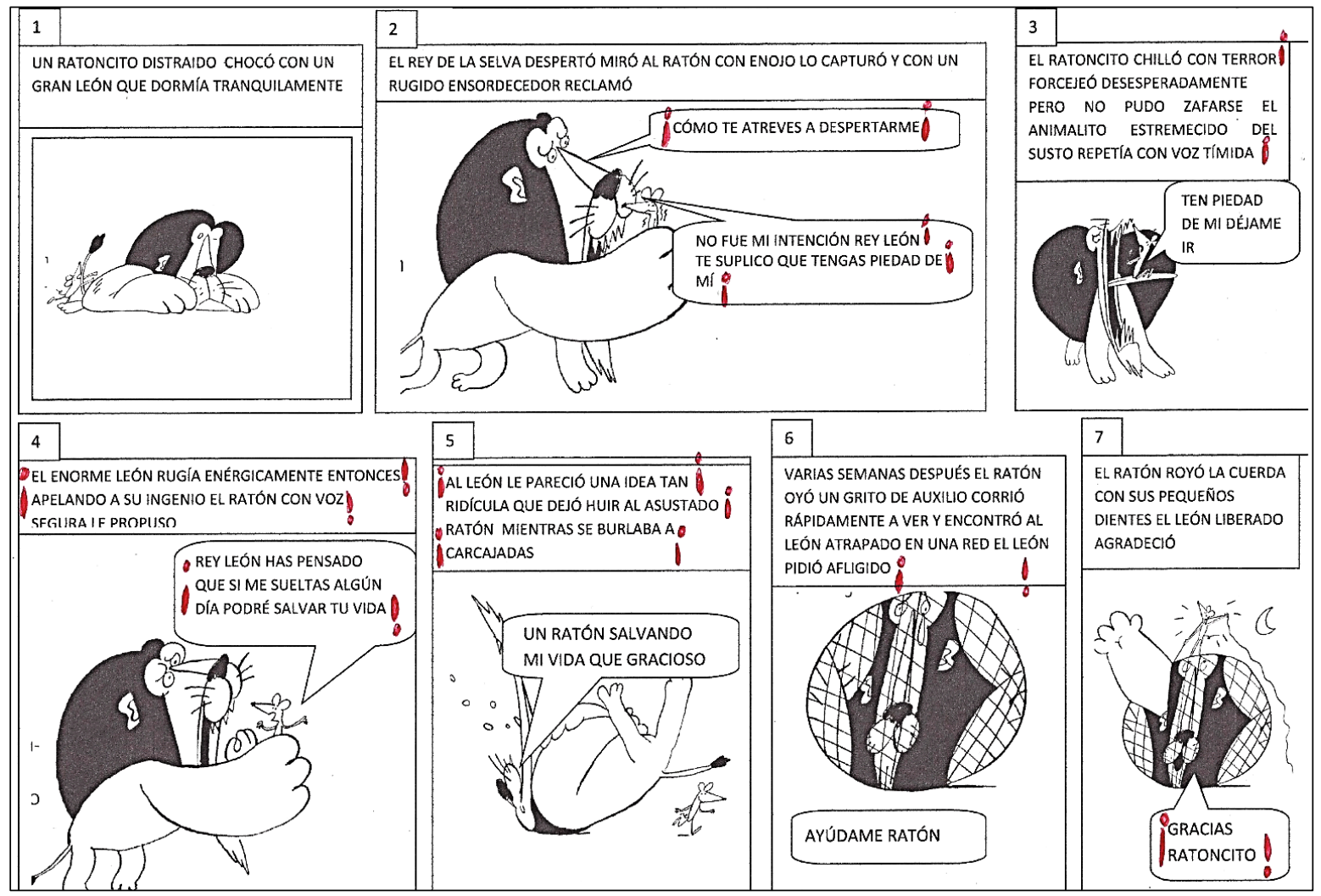

Ilustración 1. Puntuación introducida por Mercedes, $2^{\circ}$ de primaria

Lo que aparece en la Ilustración 1 es la producción de Mercedes, una niña de $2^{\circ}$ grado que pone una enorme cantidad de signos de admiración en todas las viñetas, particularmente en la primera y segunda viñeta de la parte inferior. La cantidad de signos hace suponer falta de control. Sin embargo, tomando en serio lo que hizo, preguntándole, ocurre lo siguiente.

En la viñeta donde el ratoncito dice REY LEÓN HAS PENSADO QUE SI ME SUELTAS ALGÚN DÍA PODRÉ SALVAR TU VIDA, hay dos grandes signos de admiración, uno que abre y otro que cierra. También hay signos de exclamación en la parte del narrador. Mercedes nos explica que son signos de enojo. Dice "son de enojo / para que se escuchen así / para que sepan que este tipo de cosas que dicen aquí van a hacer enojar a los que la leen / porque esto no se cree / cómo que lo dejó ir si se despertó? / los leones no son así” (Ilustración 2). Esta no es la puntuación del 
discurso de los personajes. Es la puntuación del lector, un lector que dice "esto no es posible, en esta historia yo no puedo entrar porque los leones no son así". 1

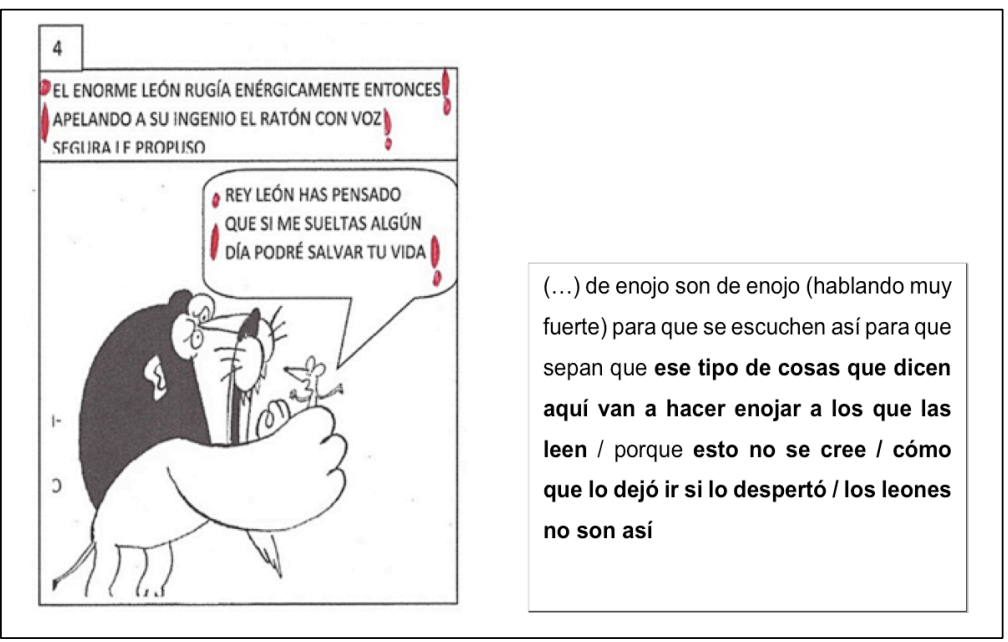

Ilustración 2. Explicación de Mercedes, $2^{\circ}$ primaria, sobre signos de exclamación en viñeta 4

Eso ocurre con signos de exclamación y también con signos de pregunta. Veamos los signos interrogativos que pone Sebastián, $2^{\circ}$ de primaria, al final de la historieta (Ilustración 3).

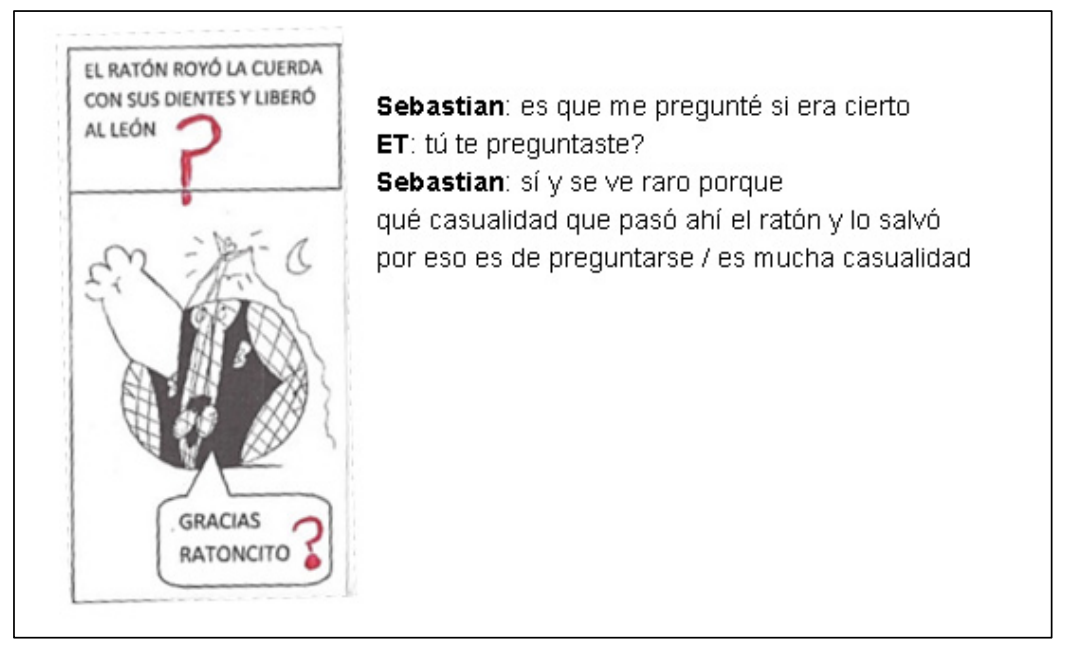

Ilustración 3. Explicación de Sebastián, $2^{\circ}$ de primaria, sobre puntuación de la última viñeta

Cuando se le pregunta a Sebastián por qué usó ese signo, responde "es que me pregunté si era cierto”. El adulto le dice “¿tú te preguntaste?” y Sebastián “sí y se ve raro / porque qué casualidad que pasó por ahí el ratón y lo salvó / por eso es de preguntarse / es mucha casualidad”. 
Este y el anterior ejemplo me parecen realmente extraordinarios a propósito de la discrepancia que puede existir entre mirar la producción y concluir: "esta es una puntuación fuera de control" o animarse a suponer que, incluso en casos como éstos, puede haber una razón. En el ejemplo de Mercedes, la profusión de signos de admiración lleva a suponer falta de control. En el caso de Sebastián, porque en un "gracias ratoncito", donde se esperaría una admiración, resulta que pone una interrogación; pero esa interrogación no corresponde a la enunciación del león; es la interrogación del lector, de Sebastián como lector, que nos hace saber que él piensa que no es creíble lo que aparece en esa historia, es demasiada casualidad que justo el ratón pasara por ahí para roer la cuerda.

Como nos atrevimos a preguntar a los niños por qué puntuaron de esa manera, nos enteramos de algo que es un descubrimiento muy reciente, que apenas está en curso de publicación como resultado de investigación y que les transmito como primicia: hay una puntuación del lector en etapas iniciales (Dávalos, 2017; Dávalos y Ferreiro, 2017). Digo etapas iniciales porque estos son chicos de $2^{\circ}$ grado que fueron interrogados al inicio del año escolar; o sea, casi son de fines de primer grado. Era una apuesta bastante fuerte saber si serían capaces de puntuar una historieta que es un texto complicado desde el punto de vista enunciativo. Estos casos nos pusieron en alerta: llegar a puntuar desde el punto de vista de los personajes del texto es también un punto de llegada, no es un punto de partida.

Para entender esto, lo mejor es recurrir a Umberto Eco quien tiene la virtud de decir de manera muy clara y en pocas líneas, cosas bastante complicadas. En un libro muy interesante que se llama Seis paseos por el bosque narrativo (1994), dice algo que ayuda mucho a entender las respuestas de estos dos niños que presentamos. Umberto Eco dice (y estoy traduciendo directamente del italiano):

La regla fundamental para afrontar un texto narrativo es que el lector acepte tácitamente un pacto ficcional con el autor, lo que Coleridge llamaba "la suspensión de la incredulidad". El lector debe saber que se trata de una historia imaginaria, sin que eso implique que el autor miente. Simplemente, como dice Searle, el autor hace como si hiciera un afirmación cierta. Nosotros aceptamos el pacto ficcional y hacemos como si creyéramos que lo que el autor cuenta realmente sucedió. ${ }^{2}$

Lo que nos dicen los niños de los dos ejemplos es equivalente a esto: no me has dado las condiciones para que yo entre en el pacto ficcional, no puedo entrar, no puedo llegar a creerlo; sí 
acepto que el león habla y que el ratoncito habla, de acuerdo, pero todo tiene sus límites; para que yo pueda entrar en el pacto ficcional me tienes que dar otras condiciones de credibilidad.

\section{Cuarta dificultad: tomar en cuenta el pensamiento infantil es necesariamente admitir que ese pensamiento evoluciona}

Eso es fácil de aceptar, pero no es fácil aceptar el siguiente problema: no siempre evoluciona en el sentido de que aumentan las respuestas correctas. Esto sí que es, de verdad, muy difícil de aceptar. Voy a utilizar algunos de los datos de la muy interesante tesis de doctorado de Mónica Alvarado, una exalumna y ahora colega de la Universidad Autónoma de Querétaro, México, quien trabajó sobre la escritura de números en un contexto no numérico. Me explico enseguida. Quiero utilizar estos resultados, que aún no han sido suficientemente difundidos y valorados, porque son muy pertinentes para discutir este tema.

Primero, les tengo que presentar una de las situaciones de indagación de la tesis de doctorado de Mónica. El punto de partida fue muy simple, aparentemente: pedir a niños de cuatro o cinco años que escriban "números que todavía no te enseñaron a escribir". Por si ustedes no lo saben, o para que lo recuerden los que sí lo saben, ese fue exactamente el punto de partida de muchos de los descubrimientos que hicimos hace tiempo. En lugar de pedir a los niños "¿qué te enseñaron a escribir?, pues escríbelo”, dimos vuelta la pregunta y dijimos "¿ya te enseñaron a escribir mariposa?, pero alguna idea debes tener, prueba a escribirlo". Con esta u otras palabras "desconocidas" en su forma escrita empezamos a asistir a la construcción de escrituras, según lo que los chicos iban entendiendo de la escritura. Pudimos pasar de la escritura como copia diferida a la escritura tal como los chicos la van entendiendo en el curso del desarrollo.

En el caso particular de la tesis de Mónica Alvarado, se trataba de encontrar un buen contexto para que los números funcionaran como nombres; no como cantidades sino como un nombre expresado con números (Alvarado y Ferreiro, 2000 y 2002; Ferreiro, 2007). Los niños de nuestra época saben muy bien que para llamar a cualquiera hay que poner una serie de números en el teléfono fijo o el celular que funcionan, mágicamente, para lograr esa comunicación. Por eso, sugerimos la composición de una lista de teléfonos de emergencia. Eso nos permitía tener letras de un lado y números del otro lado. La lista utilizada fue la siguiente (Tabla 1). 
Tabla 1. Lista de nombres y números de teléfono dictados a niños de 4 y 5 años

\begin{tabular}{|l|l|}
\hline \multicolumn{2}{|c|}{$\begin{array}{c}\text { Lista de nombres } \\
\text { y números de teléfono dictados }\end{array}$} \\
\hline Bomberos & $\mathbf{3 6} 11 \mathbf{2 5}$ \\
\hline Policía & $15 \mathbf{8 2} 20$ \\
\hline Hospital & $\mathbf{1 8} 0440$ \\
\hline Pizzas & $14 \mathbf{3 9} 93$ \\
\hline Mecánico & $12 \mathbf{5 7 6 3}$ \\
\hline
\end{tabular}

Nota: En negritas, números "transparentes" porque se comprende su modo de composición.

La manera de leer los números de teléfono varía de comunidad en comunidad y, dentro de una misma comunidad, a través del tiempo. Basta con que se agregue un número a una lista ya constituida para que tenga que cambiar el modo de decir el número. Cuando se realizó esta investigación, todos los números tenían seis dígitos y se leían de dos en dos. Dictar 361125 (treinta y seis / once / veinticinco) era normal para ese momento en esa comunidad. Bomberos, policía, hospital; las pizzas las agregaron los chicos, ¿qué clase de lista de emergencia es esa que no tiene pizzas?

Los números que propusimos son de dos tipos que clásicamente se suelen llamar transparentes y no transparentes (aunque la noción de transparencia es muy relativa, como ustedes verán). El número 36, por ejemplo, es considerado transparente porque se entiende el modo de composición: treinta y seis. En tanto que 11 es opaco porque el nombre del número no nos dice nada acerca de su modo de composición; 15 sigue siendo opaco, mientras que 16 ya es del orden de los transparentes. Los transparentes están puestos en la Tabla 1 con negritas y sobre esos voy a hablar en particular. ¿Qué hacen los chicos más chiquitos y menos desarrollados desde el punto de vista de la conceptualización de la escritura con esta propuesta?

Aprovecho para recordar algunas características que pueden presentar las escrituras presilábicas. Este es un ejemplo de pre-silábico muy avanzado (Ilustración 4). ¿Por qué? Porque tiene control de la cantidad de grafías que va a poner para cada nombre que escribe. Julián no pone largas secuencias. Todo está escrito con cuatro grafías; solo en un caso, con cinco. No solamente eso. Julián sabe escribir su nombre y las letras de su nombre sirven como repertorio básico para componer otros nombres. Escribe bomberos con las dos últimas letras de su nombre; una te, que no está en su nombre y la jota que sí está en su nombre. En la siguiente palabra, policía, usa exactamente las mismas cuatro letras de la palabra anterior pero en otro orden. 


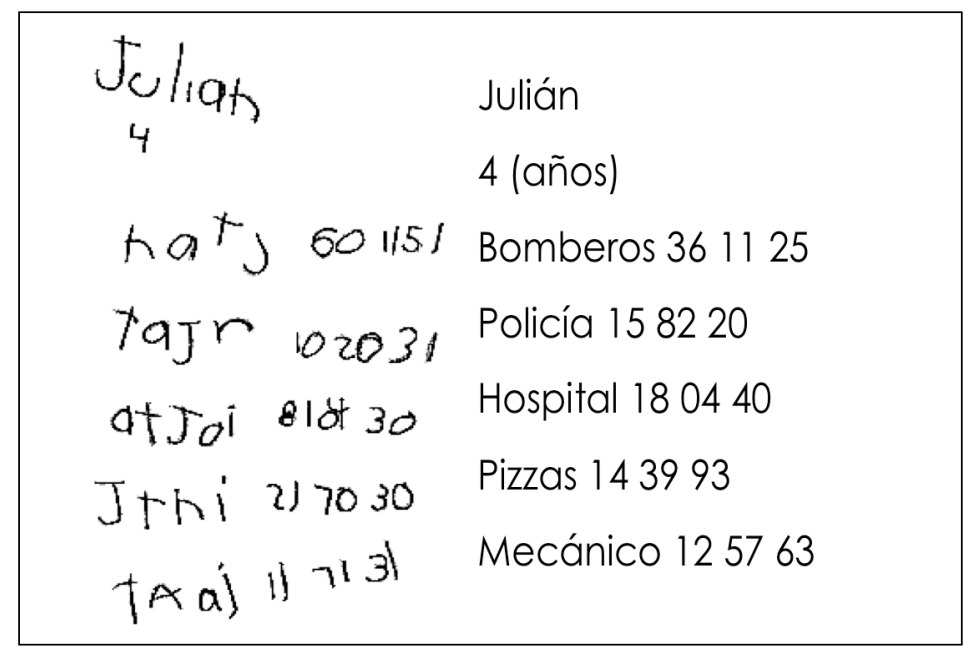

Ilustración 4. Julián, 4 años y 8 meses, nivel pre-silábico con control de cantidad

Algunos de ustedes deben saber que eso es combinatoria. Si van a los videos que están disponibles en la Cátedra de la Universidad Nacional de Rosario, van a encontrar un ejemplo estupendo de combinatoria hecha por Armando quien, escribiendo nombres de animales (no solamente los escribe sino que también los dibuja), trabaja estrictamente con cuatro caracteres, sin repetir ninguna serie. Yo no sé qué haría la escuela si tuviera que enseñar la combinatoria a los cuatro o cinco años. Es un concepto dificilísimo, que a finales de la secundaria o de la escuela preparatoria es muy difícil de enseñar. Pues aquí la vemos aparecer en la práctica. No está tematizada ni mucho menos, pero aparece espontáneamente en situaciones en donde los chicos encuentran esta solución para responder a un requerimiento interno muy fuerte: no se pueden escribir dos palabras distintas con las mismas letras en el mismo orden. ¿Quién les dijo que era así? Nadie. Es lo que ellos empezaron a construir en función de todas las escrituras con las que tuvieron contacto, seguramente, más algunos fuertes requerimientos de coherencia interna. Entre el requerimiento interno, que es fuertísimo, y el repertorio limitado de formas, la solución es la combinatoria.

Vamos a los números transparentes (Tabla 2). Curiosamente aparecen varios ceros y unos. Esto parece bastante difícil de entender. Pero vemos que en 36 está el seis; en 25 está el cinco; en 82 está el dos; en 18, parece que la serie está invertida, pero está el uno y el ocho; en 39, no se entiende qué intentó hacer; en 93, sí está el tres; en 57, está el siete y en 63, está el tres. 
Tabla 2. Julián, 4 años y 8 meses, escritura de números transparentes

\begin{tabular}{|c|c|}
\hline \multicolumn{2}{|c|}{ Escritura de números transparentes } \\
\hline Números dictados & Julián (pre-silábico) \\
\hline 36 & $\mathbf{6 0}$ \\
\hline 25 & $\mathbf{5 1}$ \\
\hline 82 & $\mathbf{2 0}$ \\
\hline 18 & $\mathbf{8 1}$ \\
\hline 39 & $\mathbf{7 1}$ \\
\hline 93 & $\mathbf{3 1}$ \\
\hline 57 & $\mathbf{7 0}$ \\
\hline 63 & $\mathbf{3 0}$ \\
\hline
\end{tabular}

Nota: La escritura inicia, a la izquierda, con el número audible del número compuesto; a la derecha de ese número, apenas 0 o 1 .

Ahora escuchemos a Julián. Cuando se le dicta 25, Julián dice “entonces es de cinco y así”. Cuando dice "y así", pone el [1] y explica la regla general: "si es veintisiete le pones el siete, si es veintitrés le pones el tres y así, te fijas cuál dices”. Ocurre que Julián y otros niños pusieron un [1] o un [0] para el número que no sabían cuál era pero no lo nombraban, ni como uno ni como cero; simplemente decían "y así". "Asi" es una expresión deíctica utilizada por los niños exclusivamente para los comodines, porque estos son números que están en el lugar de otro número, que no saben cuál es.

La Tabla 2 muestra lo que ocurre con los números transparentes. ¿Qué ocurre con los otros? Cuando se trata de números no transparentes como 11, 15... aparecen dos comodines. Veamos un fragmento del protocolo (Ilustración 5). Julián está escribiendo 15, 82 y 20. Para quince escribe [1] y [0] y dice "es de estos, creo"; de estos que no nombro. Con ochenta y dos dice "es el del dos, ves, ahora sí lo dijiste; es de dos y éste", señalando el comodín. Con veinte Julián protesta "ahora no lo dijiste"; intenta la combinación [01], mira el resultado final, dice “puro repetido" y reemplaza algunos números. 


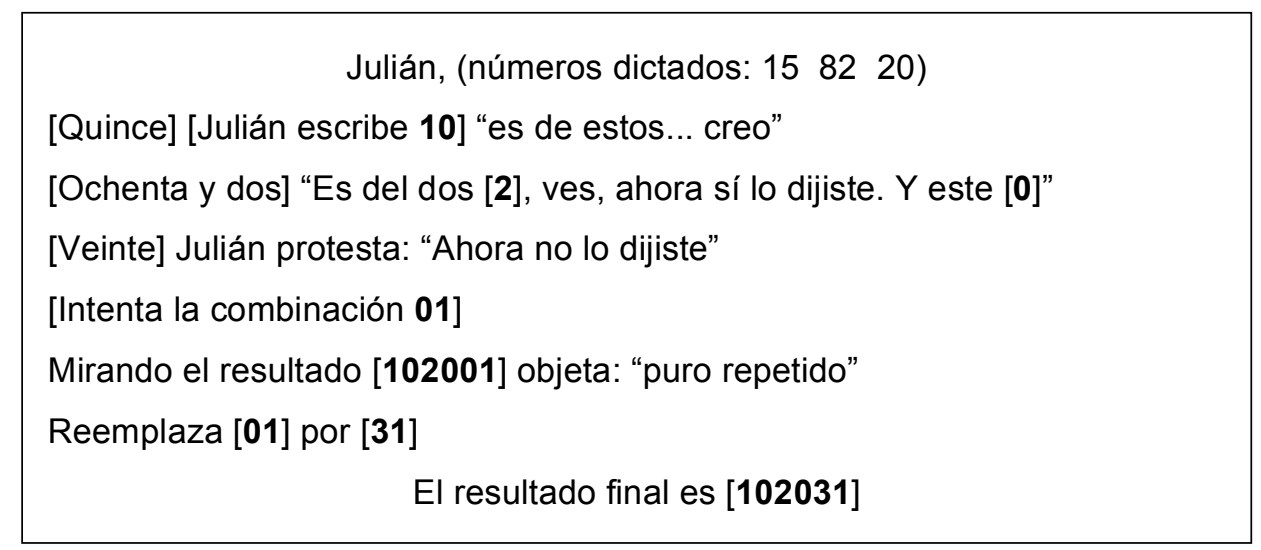

Ilustración 5. Escritura y justificaciones de Julián sobre números no-transparentes

Hay dos cosas sumamente interesantes. Primero, la noción de comodín; ya sabíamos que había letras que podían funcionar como comodines, pero no sabíamos que había números que podían funcionar como comodines. En este caso los comodines son números que están siendo utilizados sin valor propio y que adquieren el valor que corresponde a las circunstancias. Lo realmente impresionante es que los números que aparecen con valor de comodín son 0 y 1 , o sea, los números que los niños de estas edades consideran problemáticos en términos de "cantidad" (cero cantidad es conceptualmente inadmisible; 1 es la unidad, no es todavía una "cantidad").

Volvamos a la gran pregunta temática. Debemos reconocer la presencia de dos dificultades insoslayables: admitir que los niños piensan y que ese pensamiento nos concierne porque lejos de ser azaroso muestra regularidades. No solamente muestra regularidades, sino que estas regularidades nos enfrentan con otras lógicas del pensar acerca de objetos de conocimiento sobre los cuales, nosotros adultos, tenemos certezas inamovibles. Si además agrego la variable se trata de modos de pensamiento en evolución, el asunto se vuelve demoníaco, porque no entiendo cómo piensan lo que piensan y además debo entender una evolución que tampoco sigue pautas precisas de acercamiento a lo que debieran pensar.

El problema es grave porque no se trata de una evolución donde paso a paso, número por número, letra por letra, palabra por palabra, los niños se van acercando a la normatividad. Esta es la siguiente dificultad que quiero comentar. 


\section{Quinta dificultad: hay avances conceptuales que se reflejan en retrocesos en la ejecución}

¿Cómo podemos conceptualizar como más desarrolladas algunas respuestas que se distancian de las realizaciones convencionales?, ¿bajo qué condiciones podemos afirmar que un dato de ejecución es evolutivamente superior a pesar de una evaluación objetiva en sentido contrario? Para decirlo en términos coloquiales: ¿cómo me puede usted decir que este chico está avanzando si antes lo escribía bien y ahora lo escribe mal?

Comienzo con dos ejemplos de escritura del nombre propio. Los niños que se llaman MIGUEL aprenden, como todos los chicos, a reproducir las letras de su nombre en cierto orden, sin comprender el motivo de ese orden. Pero llega un momento de preocupaciones alfabéticas y ortográficas. Y la U muda después de la G es literalmente incomprensible. Nos dicen: "yo no me llamo Mi-gu-el" (pronunciando la U) y proponen MIGEL como la correcta escritura de su nombre.

Eso pasa también en períodos evolutivos previos, ustedes lo saben muy bien. Les doy un ejemplo que me gusta mucho de Giulio, un italiano. Giulio sabía escribir su nombre; al intentar leerlo, problema. Empieza "Giu" sobre la primera letra, "lio" sobre la segunda, le quedan cuatro letras sin interpretar. Intenta nuevamente, "Gi-u-lio", una sílaba para cada letra y todavía le sobran letras. Otro intento, "Giu-lio", saltándose todas las del medio; ahí se detiene y dice $M a$ perché m'a scritto questo nome mamma!! Mi poteva chiamarme in un altro modo. Dificultades similares puedo reconocer en niños mexicanos, pero jamás esta invocación a la mamma, responsable de todo lo bueno y lo malo, tan presente en la cultura italiana.

Aprovecho eso para decir que en modo alguno somos insensibles a las diferencias culturales. Hasta ahora, los datos comparativos entre español, portugués, catalán, italiano y, en ciertos aspectos, con francés, japonés e inglés, nos permiten identificar procesos similares de construcción con expresiones o manifestaciones propias a cada tradición cultural. La gran distinción entre los que piensan que todo depende de la cultura y lo que yo y mis estudiantes obtenemos como datos de investigación, no consiste en tener o no tener en cuenta la cultura como gran factor de desarrollo. La diferencia consiste en lo siguiente: hay algo común en el desarrollo de los humanos, a pesar de las diferencias culturales, o nada es comparable a causa de las diferencias culturales. La razón de algunas de nuestras disputas con los culturalistas es porque yo encuentro similitudes en el desarrollo, a pesar de fuertes diferencias culturales, incluidas las 
diferencias escolares; las encuentro en niños mexicanos, italianos, argentinos y suizos, brasileros, venezolanos, etcétera.

Esa línea evolutiva común no se expresa en las realizaciones efectivas, sino en la interpretación teórica de esas realizaciones. Este es un punto importante que apenas si voy a insinuar en este momento. No se trata de que escriban las mismas palabras con las mismas letras en el mismo orden; se trata de una categorización interpretativa, que pone las diversas grafías en un plano que no es gráfico, sino conceptual: ¿exigen letras diferentes para significados diferentes?, ¿el control de la cantidad de letras está regido por dimensiones del referente o por comparaciones entre los significantes?, y etcétera, etcétera. Por eso reacciono bastante fuerte, cuando transforman una situación de indagación en una prueba de escritura (por ejemplo, pedir a los niños que escriban cuatro palabras y una frase), como si se tratara de un espacio de comprobación gráfica. Se trata de obtener datos gráficos, sí, junto con la lectura subsiguiente que es crucial, para determinar el nivel de conceptualización del sistema de escritura, lo cual es radicalmente diferente de una prueba de escritura-dictado.

Necesito regresar a los datos de Mónica Alvarado porque, siguiendo con el desarrollo, aparecen algunas cosas completamente insospechadas: la rotación voluntaria de los números para expresar las decenas.

La Ilustración 6 presenta las producciones de Javier, de 5 años y 11 meses. En la escritura de palabras se puede apreciar claramente su nivel silábico-alfabético: algunas sílabas se resuelven con dos letras y otras con una letra. Por ejemplo "bo" de bomberos se resuelve con dos letras, así como el final "os", pero la sílaba intermedia se resuelve con una única vocal; algo similar ocurre con "hospital" (osial) que, por supuesto, no exhibe ninguna $\mathrm{H}$ inicial. 


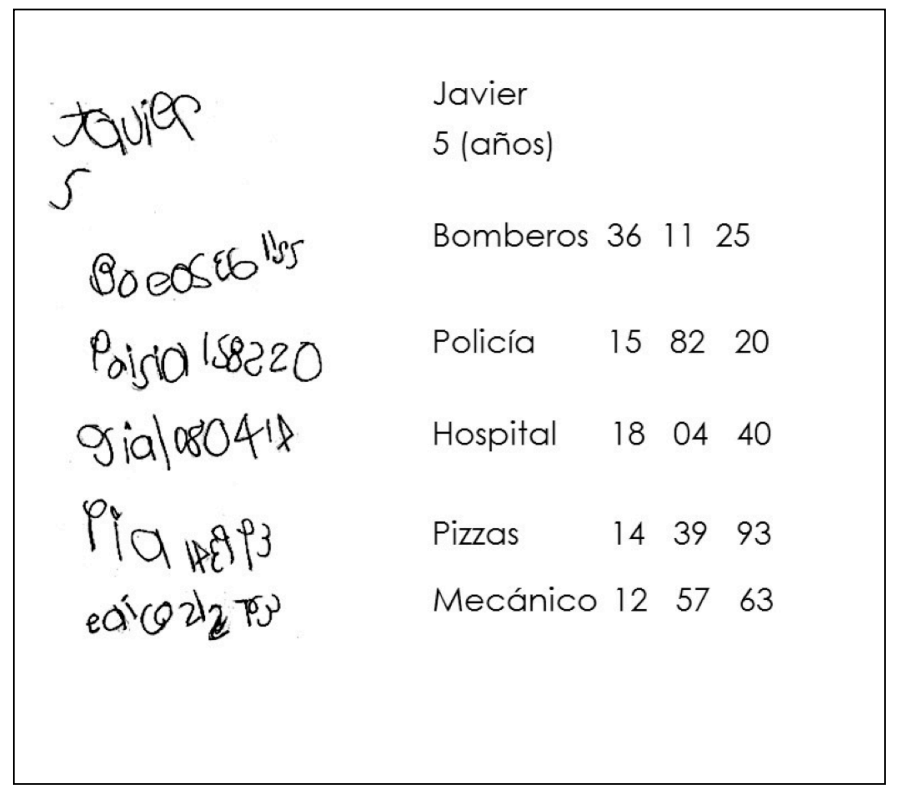

Ilustración 6. Javier, 5 años y 11 meses, nivel silábico-alfabético. Inversiones gráficas voluntarias en números

Pero detengámonos en los números, algunos de los cuales aparecen rotados. Escuchemos a Javier. Para escribir veinticinco, necesita rotar el 2. Esta forma resulta ser similar a su modo de escribir 5 y no está satisfecho. Entonces explica:

"Es del veinti y del cinco / es del veinti que se pone como dos y del cinco porque dices veinticinco"

Adulto: "Entonces ¿veinticinco se pone con dos y cinco?" Javier responde con convicción: "No / con veinti y cinco"

Para ver si esas rotaciones eran involuntarias, Mónica le pide que escriba en otra hoja el 3, el 4, el 2, el 6 y el 5. Los escribe todos perfectamente orientados y dice "bien fácil" (Ilustración 7).

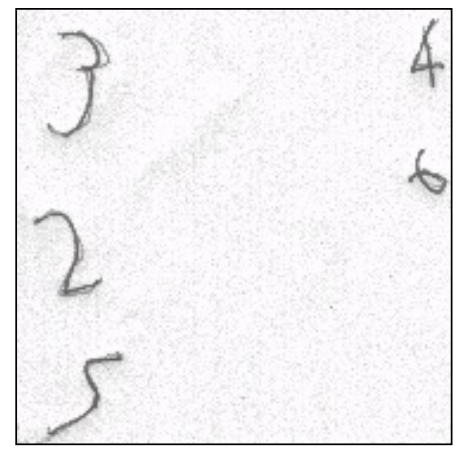

Ilustración 7. Javier, escritura de dígitos aislados 
Otro caso de rotaciones voluntarias es Jonathan de 5 años y 4 meses, de nivel alfabético. Dice: "trein-ta-i-seis. Ah, es de seis [6]. Treintai... treinta es creo de tres" [escribe un 3 rotado al lado izquierdo del 6]. El adulto pide que escriba un 3 al final de la página. Lo hace con orientación convencional diciendo "bien fácil”.

El adulto compara las dos ejecuciones del 3. Johnatan explica: "Este es de tres [3 aislado] y éste del treintaiseis. Este solito es de tres, así solito tres y este de arriba cuando se parece a tres".

Por lo tanto, la rotación del 3 es voluntaria. Es para indicar que "treinti" tiene que ver con el 3, "se parece a tres" pero no es tres.

Algunos chicos buscan números mayúsculos para poner en el lugar del treinti, del cuarenti o de lo que sea, de las decenas. También los han buscado niños norteamericanos. Bárbara Brizuela (1997) encontró algunos chicos que pedían the uppercase three. Claramente, los niños se enfrentan con la insuficiencia del sistema de representación. Si hubiera números mayúsculos, podrían usarlos en este caso; pero ocurre que el sistema no tiene números mayúsculos, quién sabe por qué. Entonces, usando los números disponibles, la rotación de la forma gráfica puede ser una solución. Explícitamente traje estos ejemplos porque las rotaciones han sido una de las maneras más fáciles de identificar disléxicos. Yo soy la voz incómoda que dice "perdón, hay de rotaciones a rotaciones". Estas son rotaciones intencionales e inteligentes, no son rotaciones fuera de control. Claro, cuando me tocó presentar estos datos en un congreso en Estados Unidos, una de las asistentes vino después y me dijo " intentional rotations?, this is too much!”. De acuerdo, "it's too much”, pero ocurre. Hay una enorme distancia entre un chico que rota sin saber que está rotando y un chico como estos que les acabo de mostrar, que intencionalmente producen rotaciones porque no encuentran otra manera de representar la diferencia entre el tres y el treinti. No todas las rotaciones se parecen, ni responden a las mismas razones.

No solamente eso. Estas inversiones voluntarias aumentan a medida que aumenta el nivel de conceptualización de la escritura (Gráfica 1). 


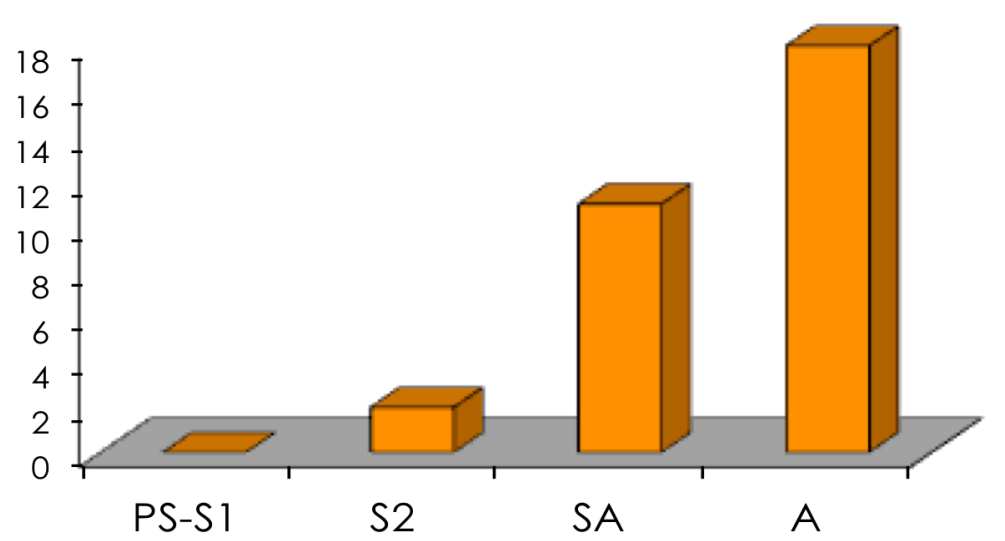

Gráfica 1. Rotaciones intencionales de los dígitos correspondientes a las decenas en números bidígitos transparentes, valores absolutos

Nota: PS = nivel presilábico; $\mathrm{S} 1$ = nivel silábico sin valor sonoro convencional; $\mathrm{S} 2$ = nivel silábico estricto, una letra por sílaba y letras pertinentes; $\mathrm{SA}=$ nivel silábico-alfabético; $\mathrm{A}=$ escrituras alfabéticas, sin restricciones ortográficas.

En los niños de nivel pre-silábico no aparecen estas inversiones voluntarias. Puede haber involuntarias, sí, no lo dudo; pero voluntarias no. Empiezan en el nivel silábico estricto, aumentan notablemente en el silábico-alfabético y los chicos prescolares de nivel alfabético recurren a esas rotaciones con mucha frecuencia. Ustedes no se pueden imaginar lo irritativo que pueden ser estos datos en ciertos ambientes y con ciertos interlocutores; mejor dicho, yo creo que sí se lo imaginan.

\section{Sexta dificultad: aceptar reflexiones muy finas de los niños sobre las insuficiencias de los sistemas notacionales que deben aprender}

El ejemplo que acabo de presentar (números rotados para paliar una insuficiencia del sistema) es pertinente, pero regreso con otros ejemplos de puntuación (Ilustración 8). 


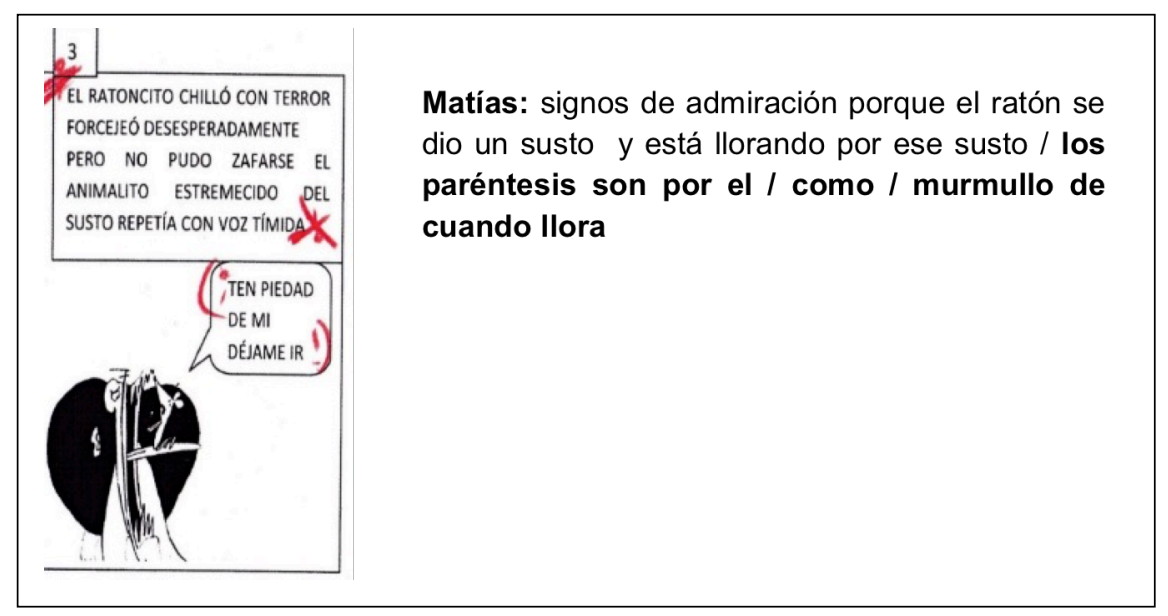

Ilustración 8. Matías, $4^{\circ}$ grado, puntuación y justificación de la viñeta 3 de la historieta El león y el ratón

En la viñeta donde el ratoncito le dice al león TEN PIEDAD DE MI, Matías dice que puso signos de admiración "porque el ratón se dio un susto y está llorando por ese susto / los paréntesis son por el / como / murmullo de cuando llora". Matías es uno de los que protestó contra la puntuación diciendo "cómo se puede poner el mismo signo de admiración al león que ruge y al ratoncito que es chiquitito y apenas si pueda chillar". Algunos protestaron diciendo "es que no encuentro cuál sería el signo de hablar quedito”. Hablar quedito en México es hablar en voz baja. Resulta que hay un signo para gritar pero ¿cuál es el signo para hablar bajito? Se puede recurrir a una combinación de signos, como hace Matías, que está utilizando los paréntesis como si fueran signos expresivos. O como hace Diana de $2^{\circ}$ grado (Ilustración 9).

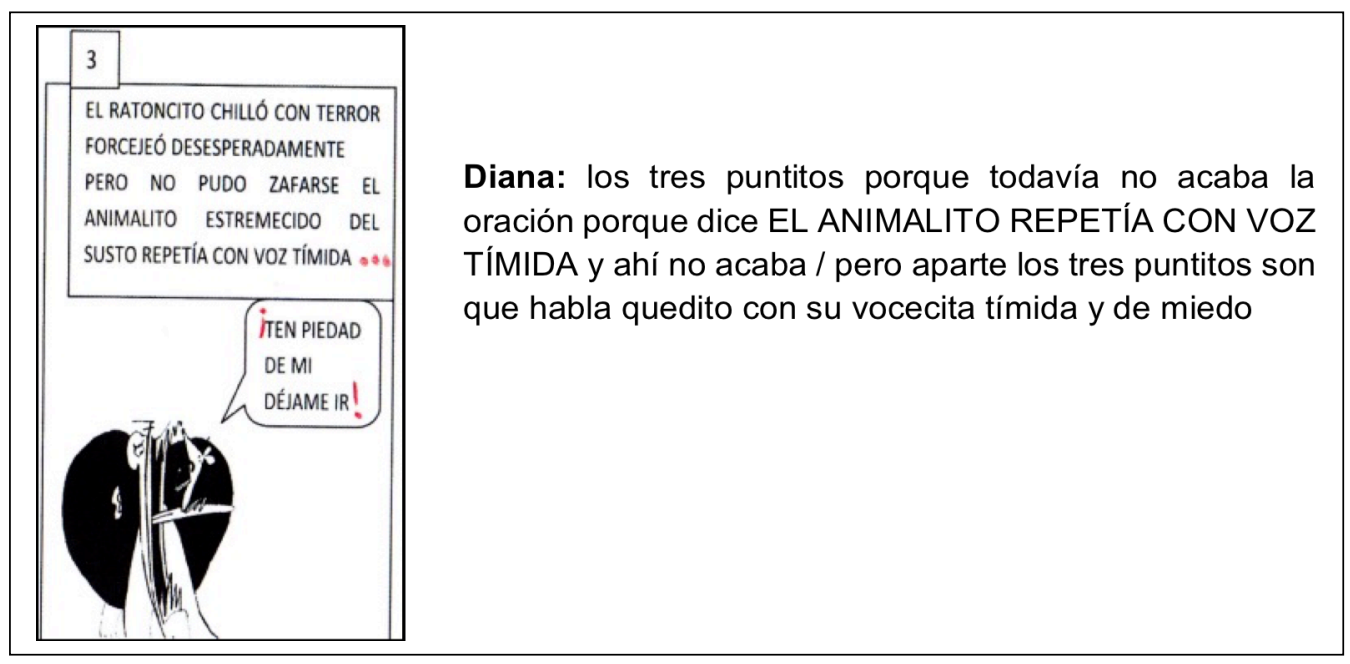

Ilustración 9. Diana, $2^{\circ}$ grado, puntuación y justificación para la misma viñeta 3 de la historieta 
Diana puso tres puntitos suspensivos en el recuadro y después admiración en TEN PIEDAD DE MI. Explica "los tres puntitos porque todavía no acaba la oración porque dice EL ANIMALITO REPETÍA CON VOZ TÍMIDA y ahí no acaba / pero aparte los tres puntitos son que habla quedito con su vocecita tímida y de miedo". Entonces tenemos algún agregado, tres puntitos, paréntesis, todos con el objetivo de encontrar un recurso de puntuación para distinguir entre el hablar fuerte, rugido de león, y el hablar quedito del ratón.

Además, hay cierta capacidad para explicar matices muy sutiles (Ilustración 10). Por ejemplo, donde el león está rugiendo y el ratoncito le dice LEÓN HAS PENSADO QUE SI ME SUELTAS ALGÚN DÍA PODRÉ SALVAR TU VIDA. Santiago, $6^{\circ}$ grado, dice “ yo puse ahí signos de interrogación porque está preguntando ansiosamente para que lo deje ir / y estos signos de pregunta son para preguntar". Un poco después dice, "no está cien por ciento preguntando / sino que es una pregunta retórica”. El adulto solicita “¿me explicas la pregunta retórica?” Santiago explica: “no está planeando que el león le responda sino que sólo está haciendo la pregunta con HAS PENSADO para que el león la piense y haga una acción / que lo suelte". O sea, no espera que le responda sino que actúe. A la pregunta “¿y esta coma?”, la que está en el medio, Santiago responde “para apartar un poco esto / es una pequeña pausa / se detiene de hablar un momento para explicar mejor / y se separe la idea de que debe pensar". Todo eso es lo esperado, pero al final miren cómo termina: "es una pausa / no siempre debes decir las cosas rápido / todo depende de qué tan claro quieres ser”.

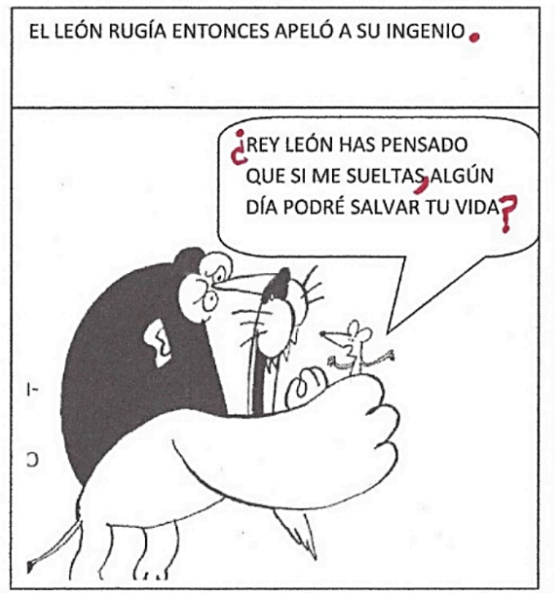

Santiago: yo puse ahí signos de interrogación porque está preguntando / este / ansiosamente para que lo deje ir / y estos signos [¿?] este son para preguntar // no está cien por ciento preguntando / sino que es una pregunta retórica

ET: me explicas la pregunta retórica?

Santiago: no está planeando que el león le responda sino que solo está haciendo la pregunta con HAS PENSADO para que el león la piense y haga una acción / que lo suelte 


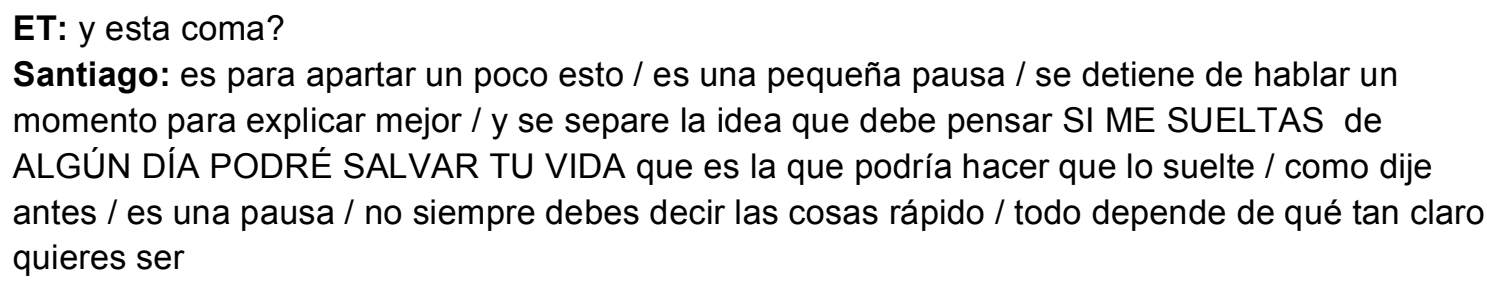

Ilustración 10. Santiago, $6^{\circ}$ grado, puntuación y justificación para la viñeta 4 de la historieta

\section{Séptima y última dificultad}

La última dificultad a la cual quiero aludir, remite a dificultades que creo vinculadas con razones propiamente ideológicas. En un momento pensé titular esta conferencia Las dificultades para asimilar la subversión que implica el pensamiento infantil. O dicho más fácil El pensamiento infantil es intrínsecamente subversivo, por eso es dificil asimilarlo teóricamente y prácticamente. La verdad es que en épocas autoritarias, donde todo viene de arriba hacia abajo, es particularmente subversivo sostener que algo puede suscitar reflexiones pertinentes viniendo de abajo hacia arriba. Para ser precisa, de la voz de los alumnos hacia la voz del docente; o más aun, hacia la voz de las autoridades que conforman a alumnos y docentes como tales.

En un momento peculiar de nuestra historia reciente, en donde una de las formas más autoritarias del pensamiento, que es el racismo, parece que se instala sin problemas en el país más poderoso de la Tierra, no es extraño que sea particularmente difícil atender a la voz de los de abajo, porque, de alguna manera, los niños son lo más abajo de los de abajo.

\section{Referencias}

Alvarado, M. y Ferreiro, E. (2000). El análisis de nombres de números de dos dígitos en niños de 4 y 5 años. Revista Latinoamericana de Lectura (Lectura y Vida), 21(1), 6-17.

Alvarado, M. y Ferreiro, E. (2002). Four- and five-year old children writing two-digit numbers. Rivista di Psicolinguistica Applicata, 2 (3), 23-37.

Alvarado, M. y Brizuela, B. (eds.) (2005). Haciendo números. Las notaciones numéricas vistas desde la psicología, la didáctica y la historia. México: Editorial Paidós.

Brizuela, B. (1997). Inventions and conventions: A history about capital numbers. For the Learning of Mathematics, 17(1), 1-6. 
Dávalos, A. (2017). Reflexiones infantiles sobre los usos y funciones de la puntuación: el papel de los marcadores de modalidad. Infancia y Aprendizaje, 40(3), 429-466. DOI: http://doi.org/10.1080/02103702.2017.1341100

Dávalos, A. y Ferreiro, E. (2017) ¿Pueden los niños de primaria reflexionar y argumentar sobre la puntuación? En F. Rossi y C. Pontecorvo (eds.), Prima alfabetizzazione. Tra percorsi di ricerca e innovazioni educative (pp. 41-56). Roma: Valore Italiano.

Eco, U. (1994). Sei passeggiate nei boschi narrativi, Milán: Bompiani.

Ferreiro, E. (1997). L'enfant après Piaget: Un partenaire intellectuel pour l'adulte. Psychologie Française, 42(1), 69-76.

Ferreiro, E. (2007). Letters and numbers in early literacy. En Y. Goodman y P. Martens (eds.), Critical issues in early literacy (pp. 59-81). Mahwah, New Jersey: Lawrence Erlbaum Associates.

\footnotetext{
${ }^{1}$ Los signos de puntuación expresivos (admiración y pregunta) no son unívocos. En particular, lo que anotamos como ¡! en español corresponde a varios estados de ánimo (sorpresa; algo inadmisible; tono de voz alto, sin otras connotaciones; admiración; etc.) Por lo tanto, no es un signo neutro sino que presupone una interpretación. A evitar cuando, precisamente, se trata de indagar las razones de los niños para usar este signo. Algo similar ocurre con puntos y comas, que no siempre corresponden a pausas de menor o mayor magnitud sino que muchas veces, al transcribir la oralidad, corresponden a cambios en el modo de enunciación. Por estas y otras razones los lingüistas atentos a la transcripción de la oralidad - entre ellos Claire Blanche-Benveniste-aconsejan evitar el uso de esos signos. Si acaso, se conserva ? como marca final, porque corresponde a un fenómeno auditivo (entonación ascendente final, marca de pregunta). Los signos de puntuación habituales se notan con / para indicar pausa corta o cambio en la intención enunciativa, y // cuando la pausa es más larga y puede corresponder a una reflexión previa al cambio enunciativo.

2 "La regola fondamentale per affrontare un testo narrativo è che il lettore accetti, tacitamente, un patto finzionale con l'autore, quello che Coleridge chiamava "la sospensione dell'incredulità". Il lettore debe sapere che quella che gli viene raccontata è una storia immaginaria, senza per questo ritenere che l'autore dica una menzogna. Semplicemente, come ha detto Searle, l'autore fa finta di fare una affermazione vera. Noi accettiamo il patto finzionale e facciamo finta che quello che egli racconta sia veramente avvenuto.”, Umberto Eco, 1994: 91-92.
}

\footnotetext{
Información sobre la autora:

Dra. Emilia Ferreiro es Investigadora Emérita del CINVESTAV e Investigadora Emérita del Sistema Nacional de Investigadores, de México. Doctora en Psicología de la Universidad de Ginebra, Suiza, con una tesis dirigida por Jean Piaget. Sus trabajos han hecho una contribución decisiva en la comprensión del proceso evolutivo de adquisición de la lengua escrita. Ha sido profesora invitada en instituciones de educación superior europeas (Universidad de Roma, Universidad Autónoma de Madrid y Ecole Pratique des Hautes Études en La Sorbona) y latinoamericanas, como el Centro de Estudios Avanzados de la Universidad de Buenos Aires, Universidad Federal de Pernambuco, Brasil, Universidad Nacional Autónoma de México y El Colegio de México, donde ocupó la prestigiosa Cátedra Jaime Torres Bodet. Emilia Ferreiro ha recibido siete Doctorados Honoris Causa (Universidades de Argentina, Brasil y Grecia). Ha sido invitada a presentar sus trabajos en conferencias internacionales en varios países de América Latina y Europa, así como en Canadá, Estados Unidos e Israel. Actualmente, sus líneas de
} 
investigación prioritarias son psicogénesis de la lengua escrita, primeras etapas y construcción textual (comprensión y producción) con énfasis en problemáticas psicológicas y lingüísticas.

Email: ferreiro@cinvestav.mx

Para citar este artículo:

Ferreiro, E. (2018). Acerca de las dificultades para aceptar que los niños piensan sobre lo escrito. Bellaterra Journal of Teaching \& Learning Language \& Literature, 11(2), 13-34. DOI: http://doi.org/10.5565/rev/jt13.769

(c) (1) 